\title{
Blockade of NMDA Receptors in the Amygdala Prevents Latent Inhibition of Fear-Conditioning
}

\author{
Cornelia Schauz ${ }^{1}$ and Michael Koch ${ }^{2,3}$ \\ ${ }^{1}$ Animal Physiology, University of Tübingen, 72076 Tübingen, Germany; ${ }^{2}$ Brain Research Institute, University of Bremen, 28334 \\ Bremen, Germany
}

\begin{abstract}
The association between a conditioned stimulus (CS) and an unconditioned stimulus (US) in fear-conditioning depends on $N$-methyl-D-aspartate (NMDA) receptors in the basolateral amygdala complex (BLA). Latent inhibition (LI) is the retardation in learning due to nonreinforced presentation of the prospective CS before conditioning. Disruption of LI in rats is an animal model of schizophrenia, reflecting the deficits of schizophrenic patients in neglecting irrelevant information. We investigated whether the BLA is involved in LI of fear-potentiated startle. Infusions of the NMDA receptor antagonist D,L-2-amino-5-phosphonopentanoic acid (AP-5; 12.5 nmoles) into the BLA before preexposure of rats to the neutral stimulus prevent LI of fear-conditioning. We also demonstrated by the same method that a complex of thalamic nuclei, comprising the medial part of the medial geniculate nucleus, the posterior intralaminar nucleus, and the suprageniculate nucleus, is involved in fear-conditioning, but not in LI. This suggests that the presentation of an innocuous stimulus during preexposure leads to an NMDA receptor-dependent change of neurotransmission in the BLA, but not in the thalamus. Our data show that the BLA but not the thalamus regulates in LI of fear-potentiated startle. Furthermore, it supports the hypothesis that the inability of schizophrenic patients to ignore irrelevant stimuli may be caused by hypofunction of the glutamatergic transmission in the brain and suggests an involvement of the amygdala in the neuropathology of schizophrenia.
\end{abstract}

Fear is a strong behavioral determinant, and, therefore, the neural mechanisms regulating this motivational state are of considerable interest. The basolateral complex of the amygdala (BLA), consisting of the lateral, basolateral, and basomedial nuclei, is crucial for the association of the unconditioned stimulus (US) and the conditioned stimulus (CS) in Pavlovian fear-conditioning (Davis 1997; Killcross et al. 1997; Fendt and Fanselow 1999; Amorapanth et al. 2000; LeDoux 2000). The association between the neutral CS and the aversive US in the BLA is probably mediated by an NMDA-receptor-dependent process of long-term potentiation (Miserendino et al. 1990; Campeau et al. 1992; Gewirtz and Davis 1997; McKernan and Shinnick-Gallagher 1997; Rogan et al. 1997).

The repeated nonreinforced presentation of a prospective CS in a preexposure stage before conditioning leads to retarded conditioning and is termed latent inhibition (LI) (Lubow and Moore 1959; Lubow 1989). LI disruption in rats may provide an animal model of the failure of schizophrenics to ignore irrelevant stimuli (Lubow et al. 1987; Gray et al. 1992; Weiner and Feldon 1997).

The precise nature of the underlying mechanisms of LI is not completely understood yet (Weiner and Feldon 1997). One possible explanation for $\mathrm{LI}$ is that preexposure

${ }^{3}$ Corresponding author.

E-MAIL michael.koch@uni-bremen.de; FAX 494212184932. Article and publication are at www.learnmem.org/cgi/doi/ $10.1101 / \mathrm{lm} .33800$. leads to a long-lasting change in information processing (possibly by forming a representation of the neutral stimulus) that interferes subsequently with acquisition or retrieval of the "CS: shock" contingency (Killcross and Balleine 1996). It is a reasonable assumption that such a process of altered neurotransmission takes place in those brain structures that are involved in conditioning or retrieval. In the case of LI of fear-conditioning, this would imply that the BLA is involved in the blunting of the association between an aversive and a neutral event. Despite the fact that the BLA receives sensory input from a variety of brain sites (Turner and Herkenham 1991), the storage of memories of neutral stimuli in the BLA has not been described so far. However, a role of the BLA in LI of fear-induced freezing in mice has been shown using the expression of the immediate-early-gene $c$-fos as a marker for changes in neuronal activity (Radulovic et al. 1998). Moreover, Falls and coworkers have shown that infusions of the NMDA receptor antagonist ( \pm )-2-amino-5-phosphonopentanoic acid (AP-5) into the BLA block extinction of fear-potentiated startle (FPS) (Falls et al. 1992). Although extinction and LI are different in terms of when the CS exposure in the absence of shock is given with respect to training, these two phenomena are otherwise procedurally identical, and both are context-specific. On the basis of these similarities, we expected that blockade of NMDA receptors in the BLA interferes with LI.

The present study investigated whether NMDA receptors in the BLA are involved in LI measured as attenuation of

LEARNING \& MEMORY 7:393-399 @ 2000 by Cold Spring Harbor Laboratory Press ISSN1072-0502/00 \$5.00

$$
\begin{array}{llllllllllllllll} 
& E & A & R & N & I & N & G & \mathbf{Z} & M & E & M & O & R & Y \\
\text { www.learnmem.org } & & &
\end{array}
$$


FPS (Schauz and Koch 1998). In FPS, a neutral stimulus is paired with a foot-shock, which leads to a potentiation of the startle response in the presence of the CS after training (Davis et al. 1993; Fendt and Fanselow 1999; Koch 1999). FPS depends on NMDA receptors in the BLA (Miserendino et al. 1990; Gewirtz and Davis 1997). According to our hypothesis, fear-conditioning is attenuated by LI when a memory trace "CS: neutral" is formed in the BLA during preexposure, which has to be overlearned during conditioning ("CS: shock").

There is evidence that subcortical pathways via the thalamus and the amygdala are involved in the processing of emotionally significant stimuli (Weinberger 1993; LeDoux 1998; Morris et al. 1999). Therefore, we also addressed the question whether thalamic nuclei play a role in FPS and LI. Thalamic nuclei possibly involved in fear-conditioning comprise not only those thalamic nuclei that are directly involved in the processing of the CS (visual or auditory thalamic nuclei) and US (nociceptive thalamic nuclei), but also the associated sensory nuclei surrounding the medial geniculate body, the suprageniculate nucleus (SG), the medial subdivision of the medial geniculate nucleus (MGm), and the posterior intralaminar nucleus (PIN) (Weinberger 1993; Benedek et al. 1997; Doron and LeDoux 1999; Linke et al. 1999).

To investigate the role of the BLA in LI we locally infused the NMDA-receptor antagonist AP-5 before preexposure to the neutral stimulus. We also infused AP-5 into the PIN/MGm/SG region before fear-conditioning and before testing to assess its possible role in acquisition and expression of FPS. Furthermore, we tested a potential role of the $\mathrm{PIN} / \mathrm{MGm} / \mathrm{SG}$ region in LI by blocking NMDA receptors during preexposure.

\section{RESULTS}

LI was assessed as the attenuation of percent FPS in preexposed rats in comparison with the nonpreexposed fear-conditioned rats. The control rats received bilateral saline injections either into the BLA or into the PIN/MGm/SG before the preexposure stage, leading in the test to a significant reduction of FPS in preexposed (PE; $n=10$ ) versus nonpreexposed (NPE; $n=10$ ) animals $(p=0.02$; Fig. 1A). Seventeen rats (NPE: $n=8$; PE: $n=9$ ) received bilateral infusion of the NMDA receptor antagonist AP-5 into the BLA immediately before the preexposure stage. Intra-BLA administration of AP-5 blocks LI of FPS ( $p=0.95$; Fig. 1B). Infusion of AP-5 into the BLA does not significantly interfere with the baseline ASR magnitude (saline: 132.33 \pm 16.68 ; AP-5: $194.23 \pm 33.35 ; p=.09$ ). Sixteen rats (NPE: $n=7$; PE: $n=9$ ) received bilateral injections of AP-5 into the PIN/MGm/SG before preexposure. This treatment had no effect on LI of FPS as indicated by a significant difference between preexposed and nonpreexposed rats $(\phi=0.03$; Fig. 1C). Infusion of AP-5 into the PIN/MGm/SG did not interfere with the
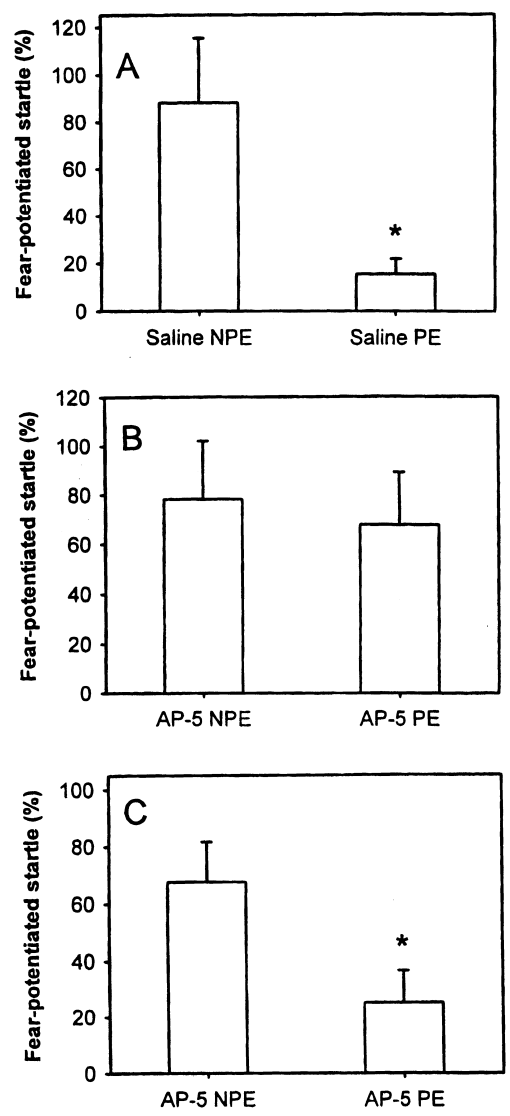

Figure 1 (A) $\mathrm{LI}$ was assessed as attenuation of percent fear-potentiated startle (FPS) in preexposed animals (PE) versus nonpreexposed animals (NPE). (B) AP-5 injected into the BLA during preexposure prevents LI of FPS. (C) Infusion of AP-5 into the PIN/MGm/ SG did not disrupt LI of FPS.

baseline ASR magnitude (saline: $132.33 \pm 18.13$; AP-5: $139.53 \pm 17.64 ; p=0.77$ )

We measured FPS as a significant increase of the ASR magnitude in the light-tone trials compared to the tonealone trials in control rats (acquisition: $n=9$; $p<0.05$; expression: $n=9 ; p<0.05$ ). To assess the role of the PIN/ $\mathrm{MGm} / \mathrm{SG}$ in acquisition of FPS with a visual CS, AP-5 was injected into the PIN/MGm/SG before conditioning. This treatment significantly attenuated the acquisition of FPS (saline: $n=9$; AP-5: $n=8 ; p=0.01$; Fig. $2 \mathrm{~A}$ ). The role of the NMDA receptors in the PIN/MGm/SG in expression of FPS was measured after administration of AP-5 before the test session. As indicated in Figure 2B, AP-5 injection also interferes with the expression of FPS (saline: $n=9$; AP-5: $n=9$; $p=0.02$ ). Furthermore, the spontaneous motor activity of the rats in the ASR test cage measured during the test was significantly attenuated in control rats, indicating freezing in control rats, but not in AP-5 rats (saline: $18.09 \pm 3.58$, AP-5: $59.91 \pm 9.32 ; p=0.001$ ). The immediate motor response during application of electric foot shocks (jumping and flinching) was measured after vehicle versus AP-5 infusion.

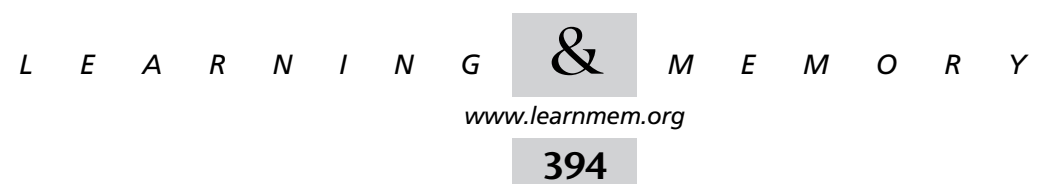



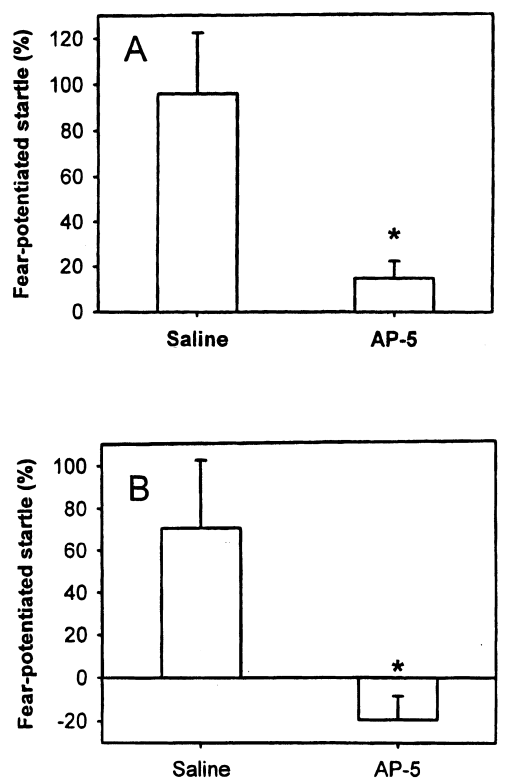

Figure 2 AP-5 injected into the PIN/MGm/SG $(A)$ before conditioning attenuated acquisition and $(B)$ before testing attenuated expression of FPS.

There was no difference in this measure of shock reactivity (saline [ $n=9$ ]: $261.06 \pm 42.61$; AP-5 [ $n=8$ ]: $290.94 \pm 34.31$; $p=0.6)$.

Serial drawings of frontal sections through the rat brain (Paxinos and Watson 1986) depict the injection sites in the BLA and in the PIN/MGm/SG in Figures 3 and 4, respectively.

\section{DISCUSSION}

The reduction in FPS after preexposure to the prospective CS was absent in AP-5 treated rats, indicating that blockade of NMDA receptors in the BLA during preexposure attenuated LI of FPS. This finding supports the hypothesis that during preexposure a representation of the "CS: neutral" situation is formed in the BLA that is inconsistent with the information acquired during conditioning ("CS: shock"). Our data show that there is an NMDA-receptor-dependent mechanism possibly involved in establishing a memory trace for a neutral, innocuous stimulus presented during preexposure. Although it is well known that the amygdala receives ample multimodal sensory input (Turner and Herkenham 1991), to our knowledge, this is the first behavioral evidence for a long-lasting change of neutral sensory information processing in the BLA.

The important role of the amygdala in the processing of aversive and pleasant memories in animals and humans is well known (Everitt and Robbins 1992; Adolphs et al. 1995; Davis 1997; Killcross et al. 1997; LeDoux 1998; Fendt and Fanselow 1999; Hamann et al. 1999); our data suggest that the BLA plays a more general role in the evaluation of cues

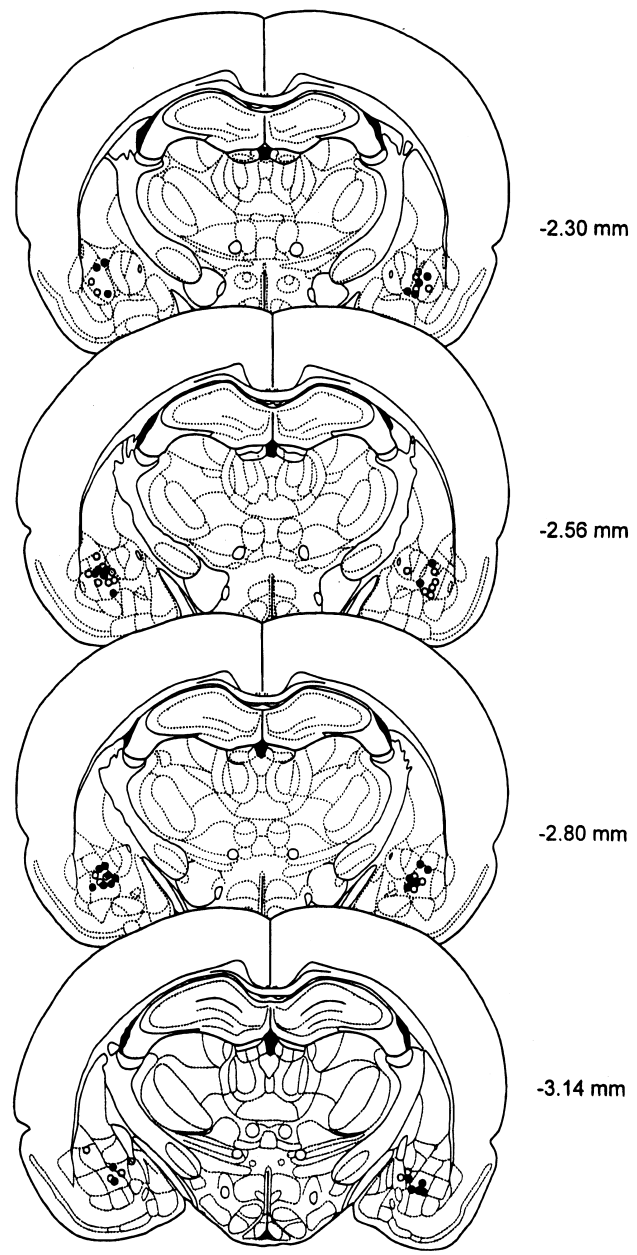

Figure 3 Serial drawings of frontal sections through the forebrain depicting injection sites in the BLA: open circles, saline; filled circles, AP-5.

and situations, implying interferences of neutral and emotional memories. Neural plasticity based on long-term potentiation within the BLA is crucial for the storage of aversive memories (Miserendino et al. 1990; Campeau et al. 1992; Gewirtz and Davis 1997; McKernan and ShinnickGallagher 1997; Rogan et al. 1997; Fanselow and LeDoux 1999). Consequently, intraamygdaloid AP-5 impairs fearconditioning only if infused before, but not after training (Maren et al. 1996; Muller et al. 1997) and muscimol-induced inhibition of the BLA affects fear memory formation before, but not after training (Wilensky et al. 1999). Furthermore, lesions given 28 days after training still produce deficits in the expression of conditioned fear, indicating storage of the association between CS and US in the BLA (Kim and Davis 1993; Lee et al. 1996; Maren et al. 1996). Although these results strongly suggest that fear memory formation is based upon a neural mechanism in the BLA, other findings indicate that the BLA is only temporarily involved in fear learning and, rather, has a modulatory role on

$$
\begin{array}{lllllllllllllll} 
& E & A & R & N & I & N & G & \mathcal{Q} & M & E & M & O & R & Y \\
\text { www.learnmem.org } & & &
\end{array}
$$




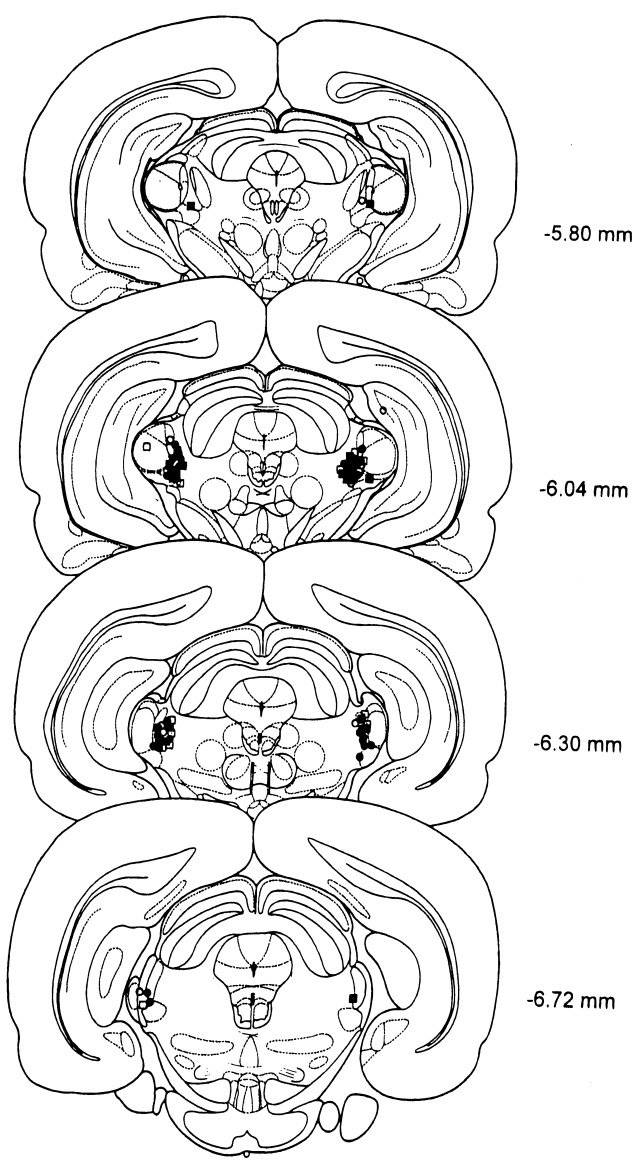

Figure 4 Serial drawings of frontal sections through the brain depicting injection sites in the PIN/MGm/SG in LI experiments (open circles, saline; filled circles, AP-5) and fear-conditioning experiments (open squares, saline; filled squares, AP-5).

the neuroplasticity in other regions of the brain, for example, in the hippocampus (McGaugh et al. 1993; Cahill et al. 1999; Vazdarjanova and McGaugh 1999). This has led to a controversy in the literature as to where in the brain aversive memories are acquired and stored (Cahill et al. 1999; Fanselow and LeDoux 1999; Amorapanth et al. 2000). Our present data show that the BLA is involved in LI of FPS possibly owing to the storage of a "CS: neutral" memory trace. This supports the contention that the BLA is also the brain site where the fear memory is formed. In contrast to the present findings using FPS, LI of a conditioned suppression procedure is regulated by the hippocampus (Weiner and Feldon 1997) and not by the BLA (Weiner et al. 1996). Since the hippocampus plays a minor role in FPS (McNish et al. 1997), we postulate that the hippocampus might not be involved in LI of FPS.

The finding of a role of the BLA in processing of neutral stimuli is interesting in the light of the fact that extinction of FPS is also blocked by AP-5 infusion into the amygdala (Falls et al. 1992). Extinction refers to the reduction of the im- perative nature of the CS after repeated nonreinforced presentation of the CS. Thus, extinction is another example for neuronal plasticity involving the evaluation of neutral stimuli by the BLA. However, here the "CS: neutral" representation is acquired after the "CS: shock" memory trace has been formed.

It has to be taken into account that the rat's ability to detect the visual stimuli could be impaired by infusion of AP-5. This possibility can be excluded based on earlier studies, which found that FPS using a visual CS is not disrupted by this NMDA receptor antagonist infused into the amygdala (Falls et al. 1992).

In addition to the importance of the amygdala in learning and memory processes, amygdala malfunction is considered to be involved in the neuropathology of schizophrenia (Reynolds 1992). Since LI can be measured in rats and humans and is impaired in schizophrenic patients and after certain experimental manipulations (e.g., administration of glutamate antagonists or dopamine agonists) also in rats, LI in animals is viewed as a valid model for schizophrenia (Lubow et al. 1987). We measured an impairment of LI after local infusion of an NMDA-receptor antagonist. The possible malfunction of glutamate transmission in schizophrenia has gained increased attention in the past few years and has led to the formulation of the glutamate hypothesis of schizophrenia (Tamminga 1998). Based on the findings of reduced glutamate levels in schizophrenic brains (Kim et al. 1980) and the psychotomimetic properties of NMDA-receptor antagonists, that is, phencyclidine (Jentsch and Roth 1999), hypofunction of the glutamatergic system was proposed to account for some aspects of the disease. The described failure of the processing of irrelevant stimuli after infusion of AP-5 into the BLA in rats may provide evidence that underfunction of NMDA receptors in the amygdala is relevant for the filtering deficits of sensory stimuli in schizophrenia.

The involvement of the PIN/MGm/SG in fear-conditioning of an acoustic CS was previously shown by a series of investigations (LeDoux et al. 1983, 1990; Campeau and Davis 1995; Heldt and Falls 1998; Weinberger 1998; Edeline 1999), but the role of the PIN/MGm/SG in fear-conditioning of a visual CS is less well elucidated (Tischler and Davis 1983). An electrophysiological study characterized the SG as a nucleus with multisensory (visual, auditory, and nociceptive) receptive field properties (Benedek et al. 1997). Moreover, anatomical data from Linke and coworkers (Linke et al. 1999) and Doron and LeDoux (1999) suggest that the PIN/MGm/SG is a possible candidate for the processing of auditory and visual stimuli in the context of fearconditioning. The reduction by AP-5 of acquisition and expression of FPS indicates an important role of the PIN/ $\mathrm{MGm} / \mathrm{SG}$ in processing of the visual CS in fear-conditioning. Diffusion of AP-5 within the PIN/MGm/SG-complex does not allow discernment of the relative contribution of these different nuclei to the behavioral effects described here.

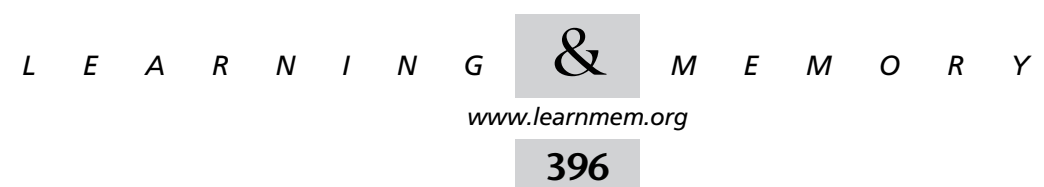


Although we found clear effects on acquisition and expression of FPS, infusing AP-5 into the PIN/MGm/SG before preexposure had no effect on LI of FPS. These data are akin to the results that lesions of the auditory thalamus abolish FPS but do not interfere with inhibition of fear after conditioned inhibition training (Heldt and Falls 1998). They also indicate that the mechanisms underlying synaptic plasticity in fear-conditioning are different in the thalamus and in the amygdala. However, there is also the possibility that the lack of effect on LI of AP-5 in the PIN/MGm/SG is caused by a reduced sensitivity of the thalamic NMDA receptor system in comparison to the BLA. The question whether there is only a quantitative rather than a qualitative difference of NMDA-receptor-mediated information processing between the PIN/MGm/SG and the BLA should therefore be tested in future experiments, where higher doses of NMDA-receptor blockers are infused into the thalamus.

The observation that FPS but not LI is impaired by AP-5 is interesting because it shows that NMDA-receptor blockade of the PIN/MGm/SG does not reduce the rat's ability to perceive visual stimuli. However, the fact that AP-5 reduced the expression of FPS clearly indicates that blockade of NMDA receptors of the PIN/MGm/SG does interfere with the processing of the visual CS after conditioning. Since a previous lesion study has shown that the PIN/MGm/SG is involved in the processing of the foot shock (Shi and Davis 1999), it is conceivable that intra-PIN/MGm/SG infusion of AP-5 might have blocked the nociceptive input during acquisition of FPS. However, our observation that AP-5 also blocked retrieval of fear, suggests that NMDA-receptor blockade in the PIN/MGm/SG specifically reduces the behavioral relevance of the visual CS. We conclude from these results that parallel pathways exist for the processing of the physical parameters of the light stimulus and of the light as a behavioral significant stimulus (McIntosh and GonzalezLima 1998) and that only visual stimuli with behavioral relevance are mediated by NMDA receptors in the PIN/MGm/ SG. This might be because of the fact that the ascending sensory input to the thalamus is mainly mediated by AMPA receptors, whereas the cortical input to the thalamus is predominantly transmitted by NMDA receptors (Salt and Eaton 1996). Thus, we assume that the visual input into the PIN/ $\mathrm{MGm} / \mathrm{SG}$ complex that is relevant for FPS is of cortical origin.

Taken together, we argue that the BLA is not only involved in the processing of emotional significant stimuli but also in the representation of neutral stimuli necessary for LI of FPS. Furthermore, we provide evidence that the PIN/ $\mathrm{MGm} / \mathrm{SG}$ is an important part of the subcortical pathway of the behaviorally significant visual CS, but is not required for the processing of the neutral CS in the LI paradigm.

\section{MATERIALS AND METHODS}

All experiments were done in accordance with international guidelines for the care and use of animals for experiments and were approved by the local council of animal care (Regierungspräsidium Tübingen, ZP 4/96). A total of 79 experimentally naive male Wistar rats (200-300 g, Charles River, Sulzfeld, Germany) were included in the statistical analysis. The animals were kept in groups of 5-6 per cage in a colony room under a 12-h light-dark cycle (lights on at 7:00 a.m.) with food and water available ad libitum.

Rats were anaesthetized with chloral hydrate $(420 \mathrm{mg} / \mathrm{kg}$ i.p.) and placed in a stereotaxic frame. After exposition and trepanation of the skull they were stereotaxically implanted with bilateral guide cannulas (22 gauge). The coordinates were $-2.8 \mathrm{~mm}$ caudal, \pm 5.0 $\mathrm{mm}$ lateral, and $8.2 \mathrm{~mm}$ ventral (BLA); and $-6.04 \mathrm{~mm}$ caudal, \pm 3.0 $\mathrm{mm}$ lateral, and $6.5 \mathrm{~mm}$ ventral (PIN/MGm/SG) relative to Bregma, flat skull position (Paxinos and Watson 1986). Stylets (27 gauge) were inserted into the cannulas to prevent them from clogging. Behavioral testing began $1 \mathrm{wk}$ after surgery.

The NMDA-receptor antagonist ( \pm )-2-amino-5-phosphonopentanoic acid (AP-5; 12.5 nmoles; RBI, Biotrend, Germany) was dissolved in saline, adjusted to $\mathrm{pH} 7.0$, and administered bilaterally immediately before the test in a volume of $0.5 \mu \mathrm{L}$ via a 27 -gauge injection cannula at a rate of $0.25 \mu \mathrm{L} / \mathrm{min}$. The injection cannula remained in the brain for another minute after infusion was completed to allow for AP-5 to diffuse into the brain parenchyma.

Preexposed (PE) and nonpreexposed (NPE) controls received saline injections immediately before the preexposure stage either into the BLA or into the PIN/MGm/SG $(n=20 ; \mathrm{NPE}=10$; $\mathrm{PE}=10$ ). Bilateral injection of AP-5 into the BLA was performed on 17 rats $(\mathrm{NPE}=8 ; \mathrm{PE}=9)$; bilateral $\mathrm{AP}-5$ injection into the PIN/ $\mathrm{MGm} / \mathrm{SG}$ was performed on 16 rats $(\mathrm{NPE}=7 ; \mathrm{PE}=9)$. To assess the effect of AP-5 on acquisition of FPS, AP-5 or vehicle was infused before conditioning (saline: $n=9$, AP-5: $n=8$ ). Expression of FPS was tested according to a within-subject latin-square design by infusing saline or AP-5 into the PIN/MGm/SG before testing $(n=9)$. After infusion of saline or AP-5 we measured shock reactivity as immediate motor response during application of foot shock. For this measurement we used 17 rats that were tested before for FPS.

In the LI paradigm, preexposure and conditioning were performed on two consecutive days, followed by a test session one day after the last conditioning trial. In the preexposure stage, each rat was placed in a dark conditioning box $\left(38 \times 60 \times 28 \mathrm{~cm}^{3}\right)$ provided with a floor made of steel bars spaced $15 \mathrm{~mm}$ apart. PE rats received 40 presentations of the prospective CS (white light, $15 \mathrm{~W}$, duration $3.7 \mathrm{sec}$, interstimulus interval $30 \mathrm{sec}$ ). Rats of the NPE group were left in the conditioning box for an identical period of time without receiving the visual CS. Both groups were then trained in the conditioning box to associate the CS with the US, a 0.6-mA electric foot shock produced by a shock generator (custom made at the University of Tübingen) presented in the last $0.5 \mathrm{sec}$ of a $3.7 \mathrm{-sec}$ white light $(15 \mathrm{~W})$. Ten pairings of CS and US were performed daily on two consecutive days. In the test session, the ASR was measured in a test box, a wire mesh cage $\left(20 \times 10 \times 12 \mathrm{~cm}^{3}\right)$ with a steel floor that was mounted on a piezoelectric accelerometer in a soundattenuated chamber. The test consisted of $5 \mathrm{~min}$ of adaptation to the startle chamber and 10 initial acoustic startle stimuli $(100 \mathrm{~dB}$, $10 \mathrm{kHz}$ pure tone of $20 \mathrm{msec}$ duration including $0.4-\mathrm{msec}$ rise and fall times) that were presented to produce a stable baseline of ASR, but were not statistically evaluated. Then 40 acoustic startle stimuli, half of them in darkness (tone-alone trials), the other half $3.2 \mathrm{sec}$ after the onset of the 3.7-sec light CS (light-tone trials) were presented in a randomized order. Background noise intensity was 55 dB SPL. To assess fear-conditioning, the whole-body ASR amplitude in darkness and in the presence of the light was calculated, respec-

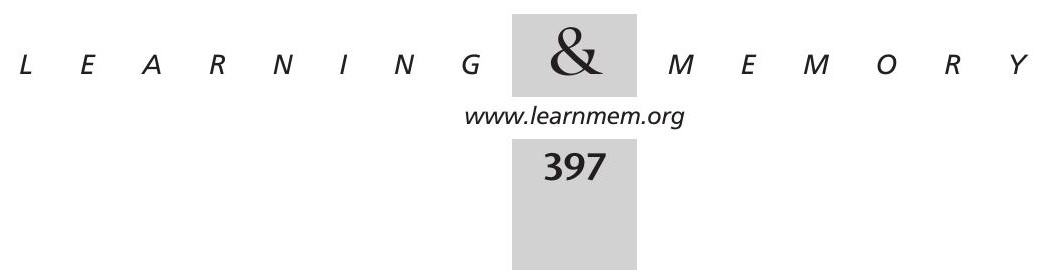


tively. LI was inferred from the difference in fear-potentiation between preexposed and nonpreexposed rats.

Rats tested for acquisition and expression of conditioned fear underwent the same behavioral procedure except for the preexposure stage. They were injected before conditioning to assess acquisition or before the test to assess expression of conditioned fear.

After completion of the behavioral studies, the rats were killed with an overdose of chloral hydrate and their brains were removed. Brains remained in a 30\% sucrose $8 \%$ paraformaldehyde solution for at least $24 \mathrm{~h}$. Then 50- $\mu \mathrm{m}$ coronal sections were taken and stained with thionin for determining the locations of the injection cannulas.

The data are presented as mean \pm SEM and were analyzed by paired $t$-tests. An alpha value of $p<.05$ was considered to represent a significant difference.

\section{ACKNOWLEDGMENTS}

This study was supported by the DFG (Graduiertenkolleg Neurobiologie, SPP 1001 and Heisenberg Programm for M. Koch). We thank Markus Fendt for helpful discussion and H. Zillus for excellent technical assistance.

The publication costs of this article were defrayed in part by payment of page charges. This article must therefore be hereby marked "advertisement" in accordance with 18 USC section 1734 solely to indicate this fact.

\section{REFERENCES}

Adolphs, R., Tranel, D., Damasio, H., and Damasio, A.R. 1995. Fear and the human amygdala. J. Neurosci. 15: 5879-5891.

Amorapanth, P., LeDoux, J.E., and Nader, K. 2000. Different lateral amygdala outputs mediate reactions and actions elicited by a fear-arousing stimulus. Nature Neurosci. 3: 74-79.

Benedek, G., Pereny, J., Kovacs, G., Fischer-Szatmari, L., and Katoh, Y.Y. 1997. Visual, somatosensory, auditory and nociceptive modality properties in the feline suprageniculate nucleus. Neuroscience 78: $179-189$.

Cahill, L.F., Weinberger, N.M., Roozendaal, B., and McGaugh, J.L. 1999. Is the amygdala a locus of "conditioned fear"? Some questions and caveats. Neuron 23: 227-228.

Campeau, S. and Davis, M. 1995. Involvement of subcortical and cortical afferents to the lateral nucleus of the amygdala in fear-conditioning measured with fear-potentiated startle in rats trained concurrently with auditory and visual conditioned stimuli. J. Neurosci. 15: 2312-2327.

Campeau, S., Miserendino, M.J.D., and Davis, M. 1992. Intra-amygdaloid infusion of the $N$-methyl-D-aspartate receptor antagonist AP5 blocks acquisition but not expression of fear-potentiated startle to an auditory conditioned stimulus. Behav. Neurosci. 106: 569-574.

Davis, M. 1997. Neurobiology of fear responses: The role of the amygdala. J. Neuropsych. Clin. Neurosci. 9: 382-402.

Davis, M., Falls, W.A., Campeau, S., and Kim, M. 1993. Fear-potentiated startle: A neural and pharmacological analysis. Behav. Brain Res. 58: $175-198$

Doron, N.N. and LeDoux, J.E. 1999. Organization of projections to the lateral amygdala from auditory and visual areas of the thalamus in the rat. J. Comp. Neurol. 412: 383-409.

Edeline, J.-M. 1999. Learning-induced physiological plasticity in the thalamo-cortical sensory systems: A critical evaluation of receptive field plasticity, map changes and their potential mechanism. Prog. Neurobiol. 57: 165-224.

Everitt, B.J. and Robbins, T.W. 1992. Amygdala-ventral striatal interactions and reward-related processes. In The Amygdala: Neurobiological Aspects of Emotion, Memory and Mental Dysfunction (ed. J.P. Aggleton), pp. 401-429. Wiley, New York.
Falls, W.A., Miserendino, M.J.D., and Davis, M. 1992. Extinction of fear-potentiated startle: Blockade by infusion of an NMDA antagonist into the amygdala. J. Neurosci. 12: 854-863.

Fanselow, M.S. and LeDoux, J.E. 1999. Why we think plasticity underlying Pavlovian fear conditioning occurs in the basolateral amygdala. Neuron 23: 229-232.

Fendt, M. and Fanselow, M.S. 1999. The neuroanatomical and neurochemical basis of conditioned fear. Neurosci. Biobehav. Rev. 23: 743-760.

Gewirtz, J.C. and Davis, M. 1997. Second-order fear conditioning prevented by blocking NMDA receptors in amygdala. Nature 388: $471-474$

Gray, N.S., Pickering, A.D., Hemsley, D.R., Dawling, S., and Gray, J.A 1992. Abolition of latent inhibition by a single $5 \mathrm{mg}$ dose of D-amphetamine in man. Psychopharmacology 107: 425-430.

Hamann, S.B., Ely, T.D., Grafton, S.T. and Kilts, C.D. 1999. Amygdala activity related to enhanced memory for pleasant and aversive stimuli. Nature Neurosci. 2: 289-293.

Heldt, S.A. and Falls, W.A. 1998. Destruction of the auditory thalamus disrupts the production of fear but not the inhibition of fear conditioned to an auditory stimulus. Brain Res. 813: 274-282.

Jentsch, J.D. and Roth, R.H. 1999. The neuropsychopharmacology of phencyclidine: From NMDA receptor hypofunction to the dopamine hypothesis of schizophrenia. Neuropsychopharmacology 20: 201-225.

Killcross, S. and Balleine, B. 1996. Role of primary motivation in stimulus preexposure effects. J. Exp. Psychol. Anim. Behav. Proc. 22: 32-42.

Killcross, S., Robbins, T.W., and Everitt, B.J. 1997. Different types of fear-conditioned behaviour mediated by separate nuclei within amygdala. Nature 388: 377-380.

Kim, J.S., Kornhuber, H.H., Schmid-Beugk, W., and Holzmuller, B. 1980. Low cerebrospinal fluid glutamate in schizophrenic patients and a new hypothesis on schizophrenia. Neurosci. Lett. 20: 379-381.

Kim, M. and Davis, M. 1993. Lack of a temporal gradient of retrograde amnesia in rats with amygdala lesions assessed with the fear-potentiated startle paradigm. Behav. Neurosci. 107:1088-1092.

Koch, M. 1999. The neurobiology of startle. Prog. Neurobiol. 59: 107-128.

LeDoux, J.E. 1998. Fear and the brain: Where have we been, and where are we going? Biol. Psychiatry 44: 1229-1238.

-2000. Emotion circuits in the brain. Annu. Rev. Neurosci. 23: $155-184$

LeDoux, J.E., Sakaguchi, A., and Reis, D.J. 1983. Subcortical efferent projections of the medial geniculate nucleus mediate emotional responses conditioned to acoustic stimuli. J. Neurosci. 4: 683-698.

LeDoux, J.E., Farb, C., and Ruggiero, D.A. 1990. Topographic organization of neurons in the acoustic thalamus that project to the amygdala. $J$. Neurosci. 10: 1043-1054.

Lee, Y., Walker, D.L., and Davis, M. 1996. Lack of a temporal gradient of retrograde amnesia following NMDA-induced lesions of the basolateral amygdala assessed with the fear-potentiated startle paradigm. Behav. Neurosci. 110: 836-839.

Linke, R., De Lima, A.D., Schwegler, H., and Pape, H.-C. 1999. Direct synaptic connections of axons from superior colliculus with identified thalamo-amygdaloid projection neurons in the rat: Possible substrates of a subcortical visual pathway to the amygdala. J. Comp. Neurol. 403: $158-170$

Lubow, R.E. 1989. Latent Inbibition and Conditioned Attention Theory. Cambridge University Press, Cambridge, UK.

Lubow, R.E. and Moore, A.U. 1959. Latent inhibition: The effect of nonreinforced pre-exposure to the conditional stimulus. J. Comp. Physiol. Psychol. 52: 415-419.

Lubow, R.E., Weiner, I., Schlossberg, A., and Baruch, I. 1987. Latent inhibition and schizophrenia. Bull. Psychonom. Soc. 25: 464-467.

Maren, S., Aharonov, G., Stote, D.L., and Fanselow, M.S. 1996. $\mathrm{N}$-Methyl-D-aspartate receptors in the basolateral amygdala are required for both acquisition and expression of conditioned fear in rats. Behav. Neurosci. 110: 1365-1374.

McGaugh, J.L., Introini-Collison, I.B., Cahill, L.F., Castellano, C., Dalmaz, C., Parent, M.B., and Williams, C.L. 1993. Neuromodulatory systems

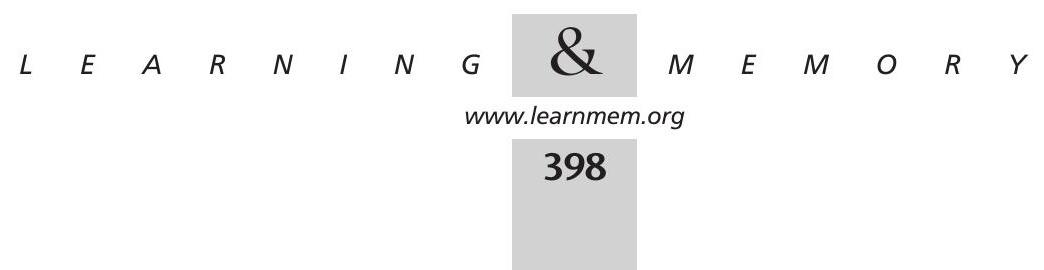


and memory storage: Role of the amygdala. Behav. Brain Res. 58: 81-90.

McIntosh, A.R. and Gonzalez-Lima, F. 1998. Large-scale functional connectivity in associative learning: Interrelations of the rat auditory, visual, and limbic systems. J. Neurophysiol. 80: 3148-3162.

McKernan, M.G. and Shinnick-Gallagher, P. 1997. Fear conditioning induces a lasting potentiation of synaptic currents in vitro. Nature 390: 607-611.

McNish, K.A., Gewirtz, J.C., and Davis, M. 1997. Evidence of contextual fear after lesions of the hippocampus: A disruption of freezing but not fear-potentiated startle. J. Neurosci. 17: 9353-9360.

Miserendino, M.J.D., Sananes, C.B., Melia, K.R., and Davis, M. 1990. Blocking of acquisition but not expression of conditioned fearpotentiated startle by NMDA antagonists in the amygdala. Nature 345: 716-718

Morris, J.S., Öhman, A., and Dolan, R.J. 1999. A subcortical pathway to the right amygdala mediating "unseen" fear. Proc. Natl. Acad. Sci. 96: $1680-1685$.

Muller, J., Corodimas, K.P., Fridel, Z., and LeDoux, J.E. 1997. Functional inactivation of the lateral and basal nuclei of the amygdala by muscimol infusion prevents fear conditioning to an explicit conditioned stimulus and to contextual stimuli. Behav. Neurosci. 111: 683-691.

Paxinos, G. and Watson, C. 1986. The Rat Brain in Stereotaxic Coordinates. Academic Press, Sydney.

Radulovic, J., Kammermeier, J., and Spiess, J. 1998. Relationship between Fos production and classical fear conditioning: Effects of novelty, latent inhibition, and unconditioned stimulus preexposure. J. Neurosci. 18: $7452-7461$

Reynolds, G.P. 1992. The amygdala and the neurochemistry of schizophrenia. In The Amygdala: Neurobiological Aspects of Emotion, Memory, and Mental Dysfunction (ed. J.P. Aggleton), pp. 255-305. Wiley-Liss, New York.

Rogan, M.T., Stäubli, U.V., and LeDoux, J.E. 1997. Fear conditioning induces associative long-term potentiation in the amygdala. Nature 390: 604-607.
Salt, T.E. and Eaton, S.A. 1996. Functions of ionotropic and metabotropic glutamate receptors in sensory transmission in the mammalian thalamus. Prog. Neurobiol. 48: 55-72.

Schauz, C. and Koch, M. 1998. Latent inhibition of fear potentiated startle in rats. Behav. Pharmacol. 9: 175-178

Shi, C. and Davis, M. 1999. Pain pathways involved in fear conditioning measured with fear-potentiated startle: Lesion studies. J. Neurosci. 19: $420-430$.

Tamminga, C.A. 1998. Schizophrenia and glutamatergic transmission. Crit. Rev. Neurobiol. 12: 21-36.

Tischler, M.D. and Davis, M. 1983. A visual pathway that mediates fear-conditioned enhancement of acoustic startle. Brain Res. 276: 55-71.

Turner, B.H. and Herkenham, M. 1991. Thalamoamygdaloid projections in the rat: A test of the amygdala's role in sensory processing. J. Comp. Neurol. 313: 295-325.

Vazdarjanova, A. and McGaugh, J.L. 1999. Basolateral amygdala is involved in modulating consolidation of memory for classical fear conditioning. J. Neurosci. 19: 6615-6622.

Weinberger, N.M. 1993. Learning-induced changes of auditory receptive fields. Curr. Opin. Neurobiol. 3: 570-577.

- 1998. Physiological memory in primary auditory cortex: Characteristics and mechanisms. Neurobiol. Learning Memory 70: 226-251.

Weiner, I. and Feldon, J. 1997. The switching model of latent inhibition: An update of neural substrates. Behav. Brain Res. 88: 11-25.

Weiner, I., Tarrasch, R., and Feldon, J. 1996. Basolateral amygdala lesions do not disrupt latent inhibition. Behav. Brain Res. 72: 73-81.

Wilensky, A.E., Schafe, G.E., and LeDoux, J.E. 1999. Functional inactivation of the amygdala before but not after auditory fear conditioning prevents memory formation. J. Neurosci. 19: RC48 (1-5).

Received May 16, 2000; accepted in revised form September 18, 2000. 


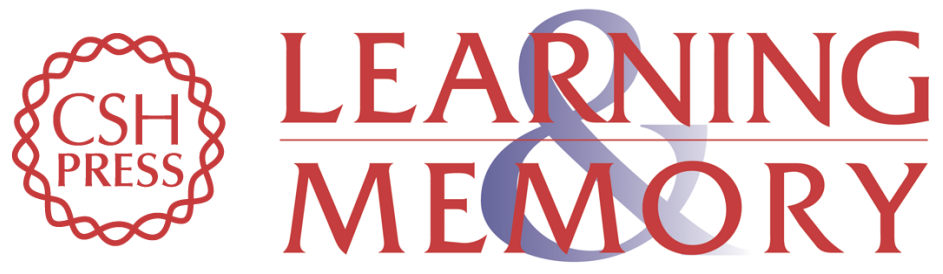

\section{Blockade of NMDA Receptors in the Amygdala Prevents Latent Inhibition of Fear-Conditioning}

Cornelia Schauz and Michael Koch

Learn. Mem. 2000, 7:

Access the most recent version at doi:10.1101//m.33800

References This article cites 52 articles, 10 of which can be accessed free at: http://learnmem.cshlp.org/content/7/6/393.full.html\#ref-list-1

License

Email Alerting Receive free email alerts when new articles cite this article - sign up in the box at the Service top right corner of the article or click here. 